\title{
Ultrasound guided simultaneous adductor canal and sciatic nerve block for intractable pain following below knee amputation
}

\author{
Shrestha BR', Khatiwada S², Shrestha U3 \\ ${ }^{1}$ Babu Raja Shrestha, Professor; ${ }^{2}$ Shikshya Khatiwada, MD Resident; ${ }^{3}$ Ujma Shrestha, Lecturer; Department of Anesthesiology \\ and Intensive care, Kathmandu Medical College Teaching Hospital, Sinamangal, Kathmandu, Nepal
}

\begin{abstract}
Ultrasound guided combined adductor canal and sciatic nerve block provides superior analgesia in extremity surgery. Prolongation of analgesia can be achieved by addition of adjuncts like dexmedetomidine.

Key words: Adductor canal, Dexmedetomidine, Ropivacaine, Sciatic nerve
\end{abstract}

\section{INTRODUCTION}

$P_{t}$ eripheral nerve blocks are frequently performed to provide perioperative analgesia in extremity surgery. However in an amputated distal extremity of a limb, adequate motor or sensory responses for nerve identification is not feasible ${ }^{1}$. In such a situation ultrasound allows advancement of the needle to the targeted nerve.

Adductor canal contains femoral artery and vein, the saphenous nerve and nerve to vastus medialis. Adequate analgesia can be achieved by the combined blockade of adductor canal and sciatic nerve.

\section{CASE}

A 42-year $52 \mathrm{~kg}$ female patient with, American Society of Anesthesiologist Physical Status underwent right below knee amputation under spinal anesthesia. Few days later she developed stump infection and severe pain. She was treated with intramuscular pethidine, intravenous ketorolac, paracetamol and tramadol. Despite multiple agents, she had excruciating pain around the amputated limb. She underwent debridement under subarachnoid block and again four hours following debridement she had developed severe pain around the amputation site, which was burning and throbbing in nature.

Address for correspondence

Dr. Baburaja Shrestha

Professor, Department of Anesthesia and Intensive Care

Kathmandu Medical College Teaching Hospital

Sinamangal, Kathmandu

E-mail: barashrestha@yahoo.co.in
Because of the excruciating nature of pain and the use of multiple drugs, we decided to perform combined sciatic nerve and adductor canal block. Monitoring with electrocardiogram, non-invasive blood pressure and oxygen saturation she was sedated intravenously with 2 mg midazolam and $25 \mu \mathrm{cg}$ of fentanyl.

Under aseptic precautions a linear ultrasound probe (10-5 MHz, Exago) was placed transversely at midpoint between the inguinal crease and medial condyle of the femur tracing the femoral artery until the boat shaped sartorius muscle was visualized (Figure 1). After identifiying the adductor canal, a $10 \mathrm{~cm} 21 \mathrm{G}$ (Stimuplex A $50^{\circ} \mathrm{B}$. Braun) needle was advanced towards the nerve using the in plane technique and $20 \mathrm{ml} 0.2 \%$ ropivacaine with $15 \mu \mathrm{cg}$ dexmedetomidine was administered on each side of pulsating artery. Then, the patient was placed in left lateral position for sciatic block. The ultrasound probe was placed transversely in the popliteal fossa to identify the popliteal artery, vein and the tibial nerve (Figure 2). After identifying the tibial nerve, the nerve was traced till common peroneal nerve was seen to have merged with it forming the sciatic nerve and $20 \mathrm{ml}$ $0.2 \%$ ropivacaine with $15 \mu \mathrm{cg}$ dexmedetomidine was deposited circumferentially around the nerve. After 15 minutes, once she had no pain around the stump, all her prescribed analgesics were withheld till she remained pain-free. She received analgesics on demand after 12 hours next day. 


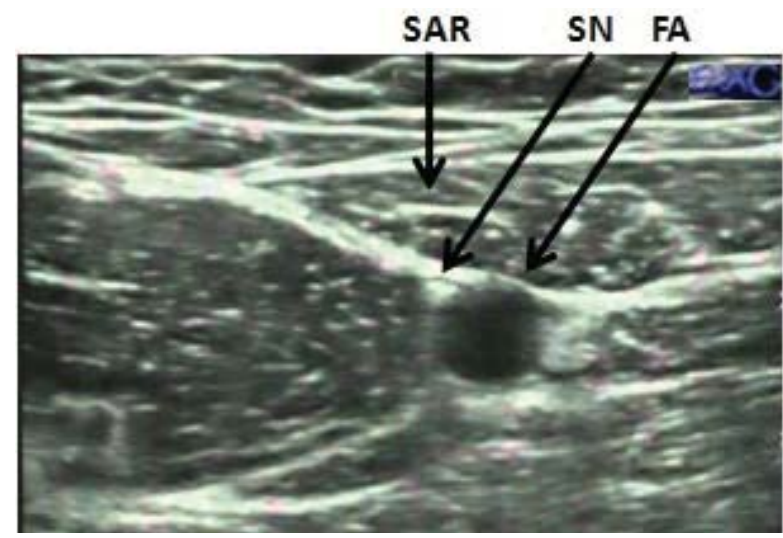

Figure 1: Transversal view of adductor canal, FA (Femoral Artery), SM (Sartorius Muscle), SN (Saphenous Nerve)

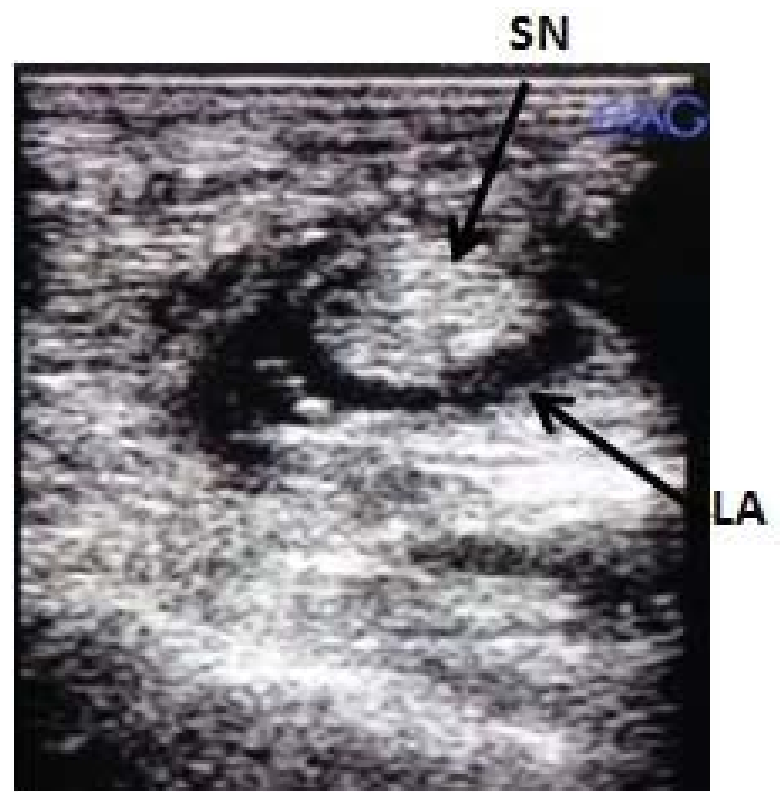

Figure 2: Transversal view of SN (Sciatic Nerve) encircled by LA (Local Anesthetic)

\section{DISCUSSION}

Nerve blocks using traditional approach or nerve stimulator is not feasible in amputees. Nerve blocks in amputees for post operative pain management pose a challenge for anesthesiologists because neurostimulation is not feasible and paresthesia is not advisable due to risk of possible progressive nerve lesions. This case report describes the use of ultrasound for the successful adductor canal and sciatic nerve identification, as it provides prolonged and good analgesia following below knee amputation. Sonographic blockade of sciatic nerve has been described for the treatment of chronic neuropathic pain of the amputation stump ${ }^{2}$. Use of ultrasound has also been described for brachial plexus block in patients with traumatic amputation of the upper limb ${ }^{3,4}$

Ultrasound guided direct visualization promotes the complete blockade of those nerves significantly reducing additional analgesia. With the above mentioned volume and concentration of ropivacaine with dexmedetomidine as an adjunct, our patient remained pain-free for 12 hours. The advantage of this technique has not only been shown to avoid multiple analgesics but also in decreasing the incidence of phantom limb sensation ${ }^{5}$. Addition of adjuncts like dexmedetomidine has been found to prolong the duration of block by upto $70 \%$ without any major side effects ${ }^{6}$.

Moreover this adjunct provides moderate sedation (Ramsay score 3 points) following an amputation of the limb surgery. The duration of analgesia of lumbar plexus and sciatic nerve block maintained for 26 hours with $20 \mathrm{ml} 0.33 \%$ ropivacaine containing $1 \mu \mathrm{cg} / \mathrm{kg}$ dexmedeomidine ${ }^{7}$. Perineural dexmedetomidine added to ropivacaine for sciatic nerve block prolongs the duration of analgesia by blocking the hyperpolarizationactivated cation current ${ }^{8}$. Dexmedetomidine may cause contraction of perineural vessel by coupling with alpha$2 \mathrm{~B}$ adrenergic receptor, reduce the absorption of local anesthetics and then prolong the duration of analgesia?.

\section{CONCLUSION}

Ultrasound can safely be used in post operative ward for enhanced precision when nerve stimulation is not practical during peripheral nerve block.

\section{REFERENCES}

1. Helayel PE, Conceicao DB, Feix C, Boos GL, Nascimento BS, Oliveira Filho GR. Ultrasound guided Sciatic-Femoral Block for the Revision of Amputation Stump. Rev Bras Anestesiol. 2008;58(5):480-4.

2. Fischier $A H$, Gross JB. Ultrasound guided sciatic neuroma block for the treatment of intractable stump pain. J Clin Anesth. 2007;19:626-8.

3. Assmann N, McCartney CJ, Turner PS, Chan VW. Ultrasound guidance for brachial plexus localization and catheter insertion after complete forearm amputation. Reg Anesth Pain Med. 2007;32:93-5.

4. Plunkett AR, Brown DS, Rogers JM, Buckenmaier CC. Supraclavicular continuous peripheral nerve block in a wounded soldier: when ultrasound is the only option. Br J Anesth. 2006;97:715-7. 
5. Borghi A, Bugamelli S, Stagni G, Missiroli M, Genco R, Colizza MT. Perineural infusion of $0.5 \%$ ropivacaine for successful treatment of phantom limb syndrome. Anestesiol. 2009;75:661-4.

6. Abdallah FW, Brull R. Facillitatory effect of perineural dexmedetomidine on neuraxial and peripheral nerve block: a systematic review and meta-analysis. BJA. 2013;15(3):1-11.
7. Wang CG, Ding $Y L$, Han AP, Hu CQ, Hao S, Zhang $\mathrm{FF}$, et al. Adding dexmedetomidine to ropivacaine for lumbar plexus and sciatic nerve block for amputation of lower limb in high risk patient. J Clin Exp Med. 2015;8(8):14184-7.

8. Upton AR, McComas AJ. The double crush in nerve entrapment syndromes. Lancet. 1973;2:359-62. 